\title{
A REVISTA CURRICULUM (1962-1976): A MEMÓRIA INSTITUCIONAL DO COLÉGIO NOVA FRIBURGO DIVULGADA COMO EXPERIÊNCIA EDUCACIONAL PIONEIRA
}

\author{
Pablo Silva Machado Bispo dos Santos ${ }^{1}$
}

\section{RESUMO}

O presente trabalho pretendeu trazer ao entendimento novos elementos de um importante periódico educacional dos anos 1960-70, a Revista Curriculum editada pela Fundação Getúlio Vargas (FGV). O estudo utilizou análise documental, combinando elementos de análise bibliométrica a técnicas de análise de conteúdo e análise retórica com vistas a desvendar os elementos da linha editorial do periódico que estavam para além de sua apresentação oficial. Ao final foi possível constatar que Curriculum funcionava (entre outras coisas) como um elemento irradiador da visão pedagógica do Colégio Nova Friburgo, vista como elemento condicionador da educação brasileira da época estudada. Palavras-Chave: História da Educação; História das Ideias Pedagógicas; Periódicos Educacionais.

\section{THE REVISTA CURRICULUM (1962-1976): INSTITUTIONAL MEMORY OF COLÉGIO NOVA FRIBURGO DISCLOSED AS A PIONEER EDUCATIONAL EXPERIENCE}

\begin{abstract}
This paper intended to bring new elements to the understanding of an important educational journal of the years 1960-70, the Revista Curriculum published by the Getúlio Vargas Foundation (FGV). The study used document analysis, combining elements of bibliometric analysis and technics of content analysis, and rhetorical analysis in order to uncover the elements of the editorial line of the journal that were beyond his official presentation. At the end, we determined that worked Curriculum (among other things) as a radiator element of pedagogical vision of Colégio Nova Friburgo, seen as an element of Brazilian education conditioner of the studied time.
\end{abstract}

Keywords: History of Education; Pedagogical History of Ideas; Educational Journals

\section{Introdução}

Este artigo consiste em uma análise do periódico Curriculum, editado pela Fundação Getúlio Vargas (FGV) no período de 1962-1976 e que possuía como principal característica o fato de estar incluída no âmbito de uma escola experimental: o Colégio Nova Friburgo da Fundação Getúlio Vargas (CNF). O estudo foi realizado tomando como base as matérias publicadas na Revista Curriculum. Tal análise se deu com o suporte de técnicas de análise bibliométrica (ALVARENGA, 1996), bem como de uma contextualização dos dados construídos à luz da noção de memória institucional ${ }^{2}$. (SANTOS, 2005). Desse modo, pressupomos que somente uma análise exaustiva dos registros da memória institucional do CNF poderia me facultar a realização do presente trabalho. Tendo em vista o processo de análise das fontes, tornou-se fundamental considerar que a investigação que desenvolvemos contemplou apenas uma das muitas possibilidades de compreensão de uma instituição escolar, especialmente num estudo que 
se assenta sobre o paradigma da História Cultural, o qual possui dentre suas várias características a ruptura com a noção de "verdade única", o que implica em reconhecer a impossibilidade de uma "narrativa única" no que se refere ao estudo de qualquer objeto histórico. (LE GOFF, 1985). Assim, procuramos tornar claro para o leitor o processo de análise e construção das interpretações sobre a memória institucional do CNF (e, de certo modo, da FGV) mediante sua Revista, bem como, a partir desta investigação procuramos verificar quais estratégias são utilizadas para caracterizar tal memória perante o cenário educacional do período.

\section{A Revista Curriculum: origens institucionais e diretrizes editoriais}

O periódico retrata parte da dinâmica da instituição, bem como se projeta como referência pedagógica para a educação brasileira da época. Esta é uma Revista que possuía como principais objetivos: a) divulgar a experiência educacional do CNF, inicialmente denominado Ginásio Nova Friburgo (GNF); b) apresentar a visão pedagógica da FGV sobre as tendências educacionais da época (em diversas dimensões, conforme poderemos constatar). A seguir, temos uma citação que indica do ponto de vista da FGV a ideia desta instituição sobre a criação do periódico:

O corpo docente do CNF, liderado pelo Prof. Amaury Pereira Muniz (...) resolveu difundir o trabalho experimental que se realizava no Colégio. Assim, nasceu a revista pedagógica do Colégio Nova Friburgo intitulada Curriculum. (CARVALHO, 1988; p. 56).

De modo a aprofundar esta caracterização dos objetivos do periódico, destacamos ainda a seguinte citação:

eram objetivos primordiais da revista Curriculum: 1) divulgar trabalhos, experiências e observações na área educacional, principalmente os realizados por professores do CNF; difundir modelos de exercícios, de planos de trabalho, de fichas e de recursos audiovisuais elaborados pelo corpo docente; 3) veicular ideias e práticas pedagógicas em voga no Brasil e em outros países que procuram inovar no campo da educação, promovendo a avaliação dessas propostas e visando ao seu aperfeiçoamento. (CARVALHO, 1988, p. 57).

Esses objetivos correspondem ao Editorial de apresentação de Curriculum, no qual o Prof. Luiz Alves de Mattos em janeiro de 1962 (a esta época o Prof. Luiz Alves de Mattos era o Diretor da Divisão de Ensino da FGV) indica quais deveriam ser as diretrizes seguidas pela Revista.

\section{A caracterização material: formato, periodicidade, número de páginas e quantidade de seções}

O periódico possui um formato retangular, com medidas que permaneceram iguais, seja em relação a seu comprimento $(22 \mathrm{~cm})$, seja em relação a sua largura $(16 \mathrm{~cm})$ durante os quinze anos de sua vida editorial. Ainda no tocante a esta vida editorial, deve ser mencionado que foram editados 45 números de Curriculum. É interessante destacar que, de 1962 a 1964, as capas do periódico traziam ilustrações relativas a grandes vultos da cultura universal $^{3}$, além de sólidos geométricos e gravuras referentes a pinturas e obras 
literárias, porém a partir do número 05, referente ao primeiro semestre do ano de 1964, é adotado novo formato de capa (que viria a permanecer até o fim do período de edição da Revista), no qual eram apresentados os títulos dos artigos e seus respectivos autores logo abaixo do título do periódico, sem apresentar ilustrações em parte alguma da capa.

No que se refere ao seu número de páginas, entre 1962 e 1966, variava entre um total em torno de 190 a 208 páginas, enquanto, entre 1967 e 1976 o número de páginas em cada edição variava entre um total de 83 e 106 páginas, o que se deve, sobretudo, à mudança em sua periodicidade, que ocorre em 1967, deixando a Revista de ser semestral e passando a ser publicada trimestralmente. A constância no formato do periódico, a regularidade das seções e, em especial, alguns aspectos marcantes da matéria publicada na Revista induzem a reflexões importantes sobre o modus operandi do CNF quanto à apresentação externa de sua memória institucional.

\section{Apresentando as seções da Revista Curriculum}

O periódico era composto das seguintes seções: Artigo, Sugestões Pedagógicas, Registro CNF e Resenhas. Ao longo de todo o período de edição de Curriculum, somente dois editoriais foram publicados: o primeiro, de autoria de Luiz Simões Lopes (Presidente da FGV à época) e intitulado "Apresentação" indicava quais seriam as diretrizes a serem seguidas na linha editorial de Curriculum, lançadas no número do periódico, datado de janeiro de 1962. O segundo editorial foi publicado no número 6 , referente ao segundo semestre, isto é, de julho a dezembro de 1964, o qual consistiu em número especial dedicado à memória do falecido (e eminente) Professor Emílio Myra y Lopez, sendo esse Editorial dedicado também à memória do referido educador, porém sem constar a assinatura de seu autor. Na seção referente às resenhas de livros, constatamos que tratavam em sua grande maioria de temas relativos à Didática, Administração Educacional, Orientação Educacional/Pedagógica e Psicologia Educacional.

De todas as seções componentes da Revista Curriculum, três merecem especial destaque: Artigo, Registro CNF e Sugestões. Na seção Artigo eram publicados ensaios e estudos de caráter acadêmico, os quais situavam os professores do Colégio Nova Friburgo e membros da Fundação Getúlio Vargas como seus principais autores. A seção Registro $C N F$, por sua vez, divulgava as atividades realizadas no $\mathrm{CNF}$, tais como: torneios esportivos, festivais de artes (literatura, poesia, artes plásticas, canto e dança), cerimônias de formatura, eventos externos em que professores o CNF fossem convidados a participar e convênios celebrados entre o CNF e outras instituições educacionais (públicas e privadas) e órgãos da administração pública ${ }^{4}$. Também eram publicados em Registro CNF eventos ocorridos em outras instituições educacionais do Brasil e de outros países. É interessante mencionar que a seção Registro $C N F$ reveste-se de importância crucial para este estudo no sentido de se apresentar como lócus privilegiado da memória desta instituição. Dando sequência à tarefa de apresentar a matéria publicada em Curriculum, será agora apresentada a seção intitulada Sugestões. Tal seção era composta por guias de atividades pedagógicas nas quais (em sua grande maioria) professores do CNF detalham atividades pedagógicas desenvolvidas no Colégio, cuja aplicação era sugerida aos professores de outras escolas que lessem a Revista. Tais Sugestões são editadas no período compreendido entre janeiro de 1968 e dezembro de 1972. 


\section{O Conselho Editorial da Revista}

Ao mapear o Conselho Editorial de Curriculum ao longo de seus quinze anos de publicação, uma característica salta aos olhos como elemento de grande relevância para um entendimento da linha de editoração deste periódico. A característica em questão dá conta do fato do Conselho não haver se alterado em toda a vida editorial da Revista, não só no que se refere aos cargos ocupados pelos seus responsáveis (Diretor e Editor-Chefe), mas também no que se refere aos nomes dos sujeitos que ocupavam os postos ${ }^{5}$. A esse respeito, Peixoto (1994) em trabalho referente à pesquisa desenvolvida com base na análise de cinco periódicos educacionais brasileiros indica que uma das características marcantes da linha editorial das publicações editadas pela Fundação Getúlio Vargas seria a constância em sua política editorial e a pouca flexibilidade no que se refere à troca de posições dos sujeitos por elas responsáveis. Segundo esta autora, tal característica se devia ao caráter patrimonialista e tradicionalista da FGV. Antes de retomar a análise da linha editorial de Curriculum, torna-se necessário que, a título de explicação, sejam trazidas as definições etimológicas dos termos supracitados, posto que configuram importantes chaves de interpretação dos dados referentes aos registros da memória institucional do CNF, presentes nos documentos estudados. No que se refere à semântica da palavra patrimonialismo, o verbete do Dicionário Houaiss (HOUAISS, 2001) indica que o termo se refere a uma:

forma de organização social que se sustenta no patrimônio considerado como conjunto de bens, materiais e não materiais, mas com valor de uso e de troca, e que podem pertencer a um indivíduo ou a uma empresa, pública ou privada. (HOUAISS, 2001).

Assim, ao aludir ao patrimonialismo da FGV, a autora estaria se referindo a uma lógica administrativa na qual os interesses financeiros e gerenciais deveriam ser atendidos prioritariamente, mesmo que isto significasse a extinção abrupta de projetos levados a cabo pela própria instituição como ocorreu com o IESAE e com mais sete órgãos daquela Fundação. (FAVERO, 2002). Associado ao patrimonialismo da FGV estaria a sua característica organizacional pautada também em um tipo de perspectiva administrativa cuja base seria a do tradicionalismo, que encontra no vernáculo da língua portuguesa (HOUAISS, 2001) as seguintes definições:

doutrina que vê na tradição a base do conhecimento e nas formas políticas e religiosas tradicionais a expressão natural das necessidades de uma sociedade, ainda que não justificáveis pela razão [...] apego às tradições ou usos tradicionais; conservadorismo". (HOUAISS, 2001, grifos nossos).

Desse modo, percebe-se que o sentido da referida palavra alude tanto a um sinônimo de conservadorismo como a uma ideologia que vê no culto às tradições uma forma de organização política, social e administrativa. A autora (PEIXOTO, 1996) associa ainda o tradicionalismo à noção de dominação tradicional, presente na obra de Max Weber, a qual proporia que a organização administrativa de uma dada instituição tende a se estruturar a partir da figura de um chefe que viria a selecionar seus colaboradores a partir da fidelidade desses à figura do líder, e que tais posições seriam ocupadas de acordo com as necessidades do chefe. Tais termos (patrimonialismo e tradicionalismo) viriam a se expressar na linha editorial da Revista Forum Educacional, na medida em que 
os ocupantes das posições dirigentes do Conselho Editorial do referido periódico não se alterariam ao longo do tempo devido ao fato de terem sido escolhidos pela direção da FGV para ocuparem tais postos. Com base nisto, entendo que a existência de uma relação entre o tradicionalismo e o patrimonialismo da FGV e a linha editorial do periódico Fórum Educacional, editado pelo Instituto de Estudos Avançados em Educação da Fundação Getúlio Vargas (IESAE/FGV), tal como assinalado por Peixoto (1996), serve como ponto de partida para uma reflexão acerca da linha editorial adotada em Curriculum pelos seus responsáveis. Isso foi feito com a finalidade de possibilitar situar os dados trazidos pela análise da composição do conselho editorial do periódico do CNF, percebido não como uma exceção, mas como uma possível marca das publicações editadas sob a égide da FGV, instituição mantenedora do Colégio Nova Friburgo, e, consequentemente, mantenedora também do periódico editado pelo Colégio.

\section{A seção "Informações Pedagógicas" e seu papel como elemento de conservação da memória do CNF}

Dentre as seções do periódico ora estudado, Informações Pedagógicas reveste-se de especial interesse no que se refere à tarefa de utilizar a Revista como fonte de investigação a respeito da história do CNF. Isto se dá por ser esta seção uma espécie de "agenda" dos eventos educacionais ocorridos no CNF, no País e no exterior.

Em relação ao modo como o conteúdo dessa seção era distribuído, cabe informar que até o ano de 1968, as "Informações Pedagógicas" eram divididas em três subseções: a) no exterior: registro de eventos educacionais, tais como: congressos, reuniões da UNESCO, encontros internacionais de educadores e outros ocorridos durante o período; b) no País: eventos educacionais, como: reuniões anuais da SBPC, congressos relativos à formação de professores, encontros de educadores ocorridos no País, com destaque aos realizados em outros estados; c) no Estado do Rio de Janeiro: registro de eventos ocorridos no Rio de Janeiro, em especial aqueles em que os professores do CNF fossem participantes. Além das referidas subseções, eram publicadas de maneira intermitente aproximadamente uma a cada dois números informações relativas a eventos ocorridos no próprio $\mathrm{CNF}$, como: torneios esportivos, festivais de poesia e palestras proferidas no $\mathrm{CNF}$ por professores deste Colégio. A partir do ano de 1969, a parte referente ao CNF passa a ocupar um papel de destaque na referida seção do periódico, passando a seção a dar mais ênfase à cobertura da atuação dos professores e da Direção do CNF. A esse respeito, é interessante notar que em Registro $C N F$ encontram-se mencionados vários convênios celebrados entre o CNF e outras instituições/órgãos do País e do exterior. Igualmente, deve ser ressaltado o fato de que continuam a ser mencionados nessa subseção eventos relativos a torneios esportivos estudantis, festivais de poesia e outros em que alunos e/ou professores e membros da direção do CNF foram objeto de distinções honoríficas (recebimento de medalhas, troféus).

Após ter procedido ao exame da matéria publicada em Informações Pedagógicas, tornou-se possível captar uma estratégia engendrada pelos editores do periódico, cuja linha de ação seria adotada no sentido de preservar a memória das realizações do CNF. Isto se daria mediante a produção de textos de caráter descritivo, entremeados de um discurso que poderia ser definido como "apologético", consistindo este numa espécie de "elogio por amplificação", por meio do qual as qualidades relativas à competência técnica e à integridade ética destes atores são constantemente mencionadas e repetidas ao longo dos textos a eles referentes.

Desse modo, somos levados a crer que dentre as estratégias empregadas pelos 
atores do CNF com o objetivo de divulgar o ideário pedagógico da instituição, estaria certamente a de marcar os pontos por eles considerados relevantes em sua trajetória por meio de um discurso elogioso e, dessa forma, tornar memoráveis as realizações do CNF ao longo do tempo e, assim influir na educação brasileira a partir da construção de uma memória na qual os educadores vinculados ao CNF surgiriam como figuras notáveis, referências para a educação no País.

\section{Análise quantitativa da matéria publicada nas seções Artigos e Sugestões}

Tendo em vista a perspectiva teórica adotada, e a proposição de captar o objeto impresso em sua materialidade (CHARTIER, 1993), após a breve apresentação da matéria publicada (principalmente a presente nas seções Artigo e Sugestões), tornou-se necessário realizar uma análise quantitativa do material impresso integrante da Revista Curriculum, o que foi realizado a partir da leitura de todos os números do referido periódico, seguida de uma aferição da frequência em que os temas e autores eram identificados nas seções da Revista relativas aos Artigos e Sugestões Pedagógicas. Essa análise quantitativa serviu de suporte a uma etapa "qualitativa" do exame da matéria publicada, em que se buscou a partir das frequências mensuradas, estabelecer relações entre a política editorial do periódico e as estratégias dos autores dos artigos (em especial daqueles vinculados ao $\mathrm{CNF}$ ) no sentido de divulgarem sua produção no cenário educacional brasileiro do período em que Curriculum é editada.

Cabe indicar que foi feita uma escolha no sentido de analisar o número de Artigos em função do ano em que estes são editados, o que se deu com o objetivo de captar a variação dos índices de incidência dos temas presentes na matéria publicada, permitindo dessa forma uma melhor compreensão dos mesmos. Assim relacionamos as variações dos temas da matéria publicada com variações na política editorial do periódico, especialmente no que tange às estratégias de divulgação do ideário do $\mathrm{CNF}$, apreendendo dessa forma, enfim o "movimento do real" (CURY, 1996), relativo ao CNF (especialmente no que tange a seu periódico).

Ao proceder à quantitativa da análise, percebe-se que ao longo de seus quinze anos de vida editorial, a Revista publicou 267 artigos (compondo uma média de aproximadamente 17 artigos por ano). No tocante à autoria dos referidos artigos, constatase que 99 autores publicaram artigos em Curriculum, com destaque para Amaury Pereira Muniz, autor que mais publicou artigos (29 ao todo). Exame preliminar do total dos artigos publicados, examinados em função do ano de edição indica que em 1962 ocorreu a maior frequência desse elemento da matéria do periódico, perfazendo um total de 27 ao longo desse ano. A ocorrência chama atenção para um dado bastante significativo, qual seja o de que o Diretor do CNF (por quinze anos) é também o autor que publica aproximadamente $10 \%$ de todos os artigos editados, o que, ao que tudo indica reforça a ideia de que no âmbito da FGV, os ocupantes das posições dirigentes de seus órgãos teriam preponderância no que se refere às diretrizes adotadas na linha editorial de periódicos editados pela FGV. No tocante à frequência do número de artigos publicados por ano, cabe mencionar que nos anos de 1966 e 1967 se dá a menor frequência de artigos publicados, sendo o seu total de 14 em cada um destes dois anos.

Com o intuito de aprofundar um pouco mais o exame da matéria da Revista Curriculum, voltamos nossa atenção para a frequência dos temas publicados nos artigos em cada ano da vida editorial do Periódico editado pelo CNF. Desse modo, verifica-se que a maior incidência de artigos no periódico foi a dos que versavam sobre Didática, sendo que no ano de 1970, alcançam o seu maior percentual no período de edição da 
Revista, atingindo a marca dos $82,3 \%$ do total de artigos publicados. Igualmente merece ser destacada a variedade dos temas abordados em cada ano, que oscila entre o número de dois temas diferentes em 1970 até o total de nove temas diferentes, identificados a partir do exame dos artigos editados em Curriculum no ano de 1974. Dentre tais temas, "Didática" é o que possui maior expressão do ponto de vista quantitativo, totalizando ao longo dos quinze anos de vida editorial de Curriculum uma frequência absoluta de 143 artigos e uma frequência relativa de 53,5\% em relação a todos os artigos editados.

Em relação aos autores que mais publicaram artigos referentes ao tema "Didática", percebemos que Amaury Pereira Muniz foi, novamente, o autor que mais se destaca, tendo publicado 21 dos 143 artigos que tratavam de Didática. No que se refere às variações desse tema ao longo do período de edição da Revista, é interessante mencionar que, no ano de 1962, Didática atinge seu maior índice de frequência absoluta (21 artigos publicados neste ano), já no ano de 1970, o tema Didática atinge o seu maior índice em termos de frequência relativa $(82,4 \%)$. No que tange a seus menores índices de frequência, o tema Didática apresenta no ano de 1973 uma frequência absoluta de apenas duas ocorrências em artigos, perfazendo uma frequência relativa de $11,1 \%$ do total dos temas presentes na seção Artigo.

As informações sobre esta quantificação servem como "pistas", indicativas do percurso traçado pela linha editorial do periódico, as quais permitem indagar em que medida a ênfase dada ao tema "Didática" consistiu em uma estratégia dos editores de Curriculum no que diz respeito à divulgação do ideário pedagógico do CNF.

Ao seguir adiante na análise da matéria da seção Sugestões, verificamos que, de um total de 105 Sugestões publicadas durante todo o período (totalizando, em média, aproximadamente 11 Sugestões por ano) em que esta seção consta da matéria de Curriculum, no ano de 1969 é publicado o maior número de elementos da seção da matéria do Periódico (14 ao todo), igualmente é possível verificar que em 1967 as referidas Sugestões atingem o menor índice de recorrência por ano de edição (08 ao todo).

No que se refere aos autores das Sugestões cabe mencionar que até 1967, não havia no periódico uma identificação individual para os autores das Sugestões, sendo estas identificadas sob a denominação genérica de "Equipe de Professores do CNF". Depois do ano de 1967 e até o último ano de sua existência, as Sugestões passam a ser identificadas por autor. A partir de então, quem mais publicou foi Maria Zely Pereira Muniz (10 ao todo).

A identificação do número de Sugestões publicadas por ano, ainda que se constitua em um ponto de partida para a análise que empreendemos, não se mostra suficiente, e, assim como foi feito em relação aos Artigos, tornou-se necessário ir adiante e proceder à identificação dos temas por ano de edição da Revista.

Ao dar sequência a esta análise, nota-se que, em relação à variedade dos temas referentes ao conteúdo da matéria presente na seção Sugestões, estes encontram seu maior índice no ano de 1971 (cinco temas diferentes por ano) e que seu menor índice é verificado no ano de 1967 (apenas dois temas diferentes por ano). Merece destaque o fato de que o tema "Didática" surge como majoritário no que se refere às frequências absoluta e relativa da matéria publicada na seção, tudo isso em índices ainda maiores do que os que foram percebidos na análise da seção Artigos. Eis os índices: de um total de 105 Sugestões, o referido tema informa o conteúdo de 86 destas, perfazendo uma frequência relativa de $81,9 \%$ dos temas publicados na seção ora analisada. Em relação à ocorrência do tema Didática tomada em função de cada ano de edição do periódico, verifica-se que no ano de 1970, o tema encontra o seu maior índice em termos de frequência absoluta, 
totalizando 13 Sugestões, no que tange à frequência relativa, Didática encontra no ano de 1970 a impressionante marca de $100,0 \%$ das Sugestões publicadas nesta seção durante este ano de edição de Curriculum. Igualmente deve ser destacado o fato de que todas as 10 Sugestões publicadas por Maria Zely Pereira Muniz incidiam sobre o tema "Didática", o que confirma uma tendência verificada na análise da matéria publicada na seção Artigos, ou seja, o autor que mais publica, acaba por fazê-lo utilizando como base o tema majoritário no contexto da matéria do Periódico.

\section{Análise qualitativa da matéria publicada nas seções Artigos e Sugestões de Curriculum}

Nesta seção procuro me apoiar nos elementos classificados, quantificados e organizados da matéria publicada nas seções Artigos e Sugestões de Curriculum, com vistas a construir uma narrativa interpretativa, voltada para a compreensão do modo como esses elementos "se comportaram" durante o período de edição da Revista, dando uma ênfase especial à forma como o CNF encontra-se representado na matéria publicada, permitindo assim reconstruir (ao menos em parte) uma narrativa da instituição a respeito de sua própria história. Assim, torna-se necessário indicar que serão relacionados vários dos elementos captados com a análise empreendida na seção anterior, r elacionados de forma a permitirem captar a coerência interna e a lógica das estratégias editoriais desse periódico editado por quinze anos por um colégio financiado por uma fundação de direito privado como a FGV. Finalmente, é preciso ainda indicar que, para que se compreenda a maneira como é realizada essa tarefa, cabe retomar um ponto de vital importância para o entendimento da maneira como é conduzida. Trata-se da contextualização da perspectiva teórica que defino e, mais especificamente, do ponto de vista em que procuro me situar para realização da análise. Assim, é de grande relevância explicitar que pretendo realizar um diálogo entre as duas dimensões que constituem uma "narrativa coerente", ou seja, "a referência aos elementos concretos" relativos ao objeto investigado, e que neste estudo referem-se aos elementos da matéria publicada na Revista e, o "diálogo entre a teoria e as fontes" no qual pretendo fazer com que o discurso captado nos referidos elementos quantificados possa trazer ao entendimento do leitor a lógica dos editores do periódico, e, tendo em vista o fato de que era editado (e, principalmente, controlado) pelos professores e pela direção do CNF, reconstruir em parte a história desses atores, responsáveis pelo projeto pedagógico e pela administração do colégio.

\section{O teor dos artigos de Didática e a influência de seus principais autores}

Os artigos agrupados pelo tema "Didática" apresentam duas características que os marcam de maneira bastante forte, permanecendo ao longo de todo o período de edição da Revista, são: a) consistirem em elemento privilegiado na linha editorial do periódico, podendo ser dito até mesmo que esse assunto constituiria a tônica da matéria publicada na seção de Curriculum, o que se infere ao perceber que o tema acaba sendo a matéria-prima em termos de conteúdo de aproximadamente 53,5\% do total de artigos publicados; b) alguns de seus principais autores são também professores responsáveis por funções administrativas de grande importância no CNF e na própria FGV; c) o teor dos artigos remonta aos aspectos técnico-operacionais da Didática, incidindo preferencialmente sobre as metodologias de ensino de disciplinas escolares (como: 
Metodologia do Ensino de Língua Portuguesa e Metodologia do Ensino de Matemática).

No que se refere à primeira característica apontada, cabe indicar que a tendência à concentração em poucos temas já foi apontada em trabalho sobre o Instituto de Estudos Avançados em Educação (IESAE/FGV), em parte que menciona a Revista Fórum Educacional, periódico editado pelo IESAE/FGV e também pela Divisão de Ensino e Pesquisa da FGV. (FÁVERO, 2002). Ao comparar a alta concentração de artigos com o tema "Didática", à já apontada constância na composição do Conselho Editorial de Curriculum, é possível concluir que durante 1962 e 1976 a manutenção do teor dos artigos e a pouca flexibilidade no que se refere às posições de poder e no que alude aos responsáveis pelo periódico editado pelo CNF fornece indicativos importantes para a compreensão, ao menos em parte, das relações existentes entre os membros dessa instituição.

Em relação à segunda das características apreendidas mediante o exame da matéria publicada na seção Artigos, é interessante perceber que, no momento em que foram identificados os autores dos artigos do tema "Didática", dois exerceram importantes funções no CNF e na FGV e respondem pela autoria de aproximadamente $30 \%$ do total dos artigos publicados. São eles: Amaury Pereira Muniz e Irene Estevão de Oliveira (posteriormente Irene Mello Carvalho). Antes de prosseguirmos a análise cabe indagar sobre quem eram esses autores. No que se refere a Amaury Pereira Muniz, torna-se necessário registrar que o professor teria exercido a função de Diretor do CNF durante 18 anos, divididos em três mandatos, a saber: de 1952 a 1953, 1958 a 1965 e de 1968 a 1977. Merece ser destacado também que durante todo o período de edição da Revista, o Diretor do CNF foi também redator-chefe do periódico. Irene Mello Carvalho por sua vez foi Diretora da Revista durante todo o período de edição, bem como Secretária executiva do Conselho de Coordenação de Ensino e Pesquisa da Fundação Getúlio Vargas (CONCEP/FGV), tendo exercido igualmente a direção da Divisão de Ensino da FGV durante a época de criação do CNF.

No que se refere à tônica dos artigos relativos ao tema "Didática", cabe ressaltar que foram escritos com um teor predominantemente descritivo, fornecendo aos leitores várias "fórmulas" a partir das quais se poderia tornar "mais eficiente" o ensino nas escolas, sendo apresentadas tais "fórmulas" como iniciativas pedagógicas de caráter experimental desenvolvidas no CNF. Essa diretriz observada na linha editorial de Curriculum mostra que o periódico durante os seus quinze anos de vida editorial foi controlado de maneira rigorosa por seus responsáveis, naquilo que se refere ao cumprimento das diretrizes por eles propostas, pois se levarmos em consideração o que a antiga Diretora do Conselho Editorial do periódico afirma em livro de sua autoria como sendo um dos principais objetivos da Revista Curriculum, ou seja, "[...] difundir modelos de exercícios, de planos de trabalho, de fichas e de recursos audiovisuais elaborados pelo corpo docente [do CNF]" (CARVALHO, 1988, p. 56), desse modo, podemos afirmar que temos a comprovação de que dois eram os mecanismos de controle empregados pelos editores de Curriculum: a) publicação de grande número de artigos por parte dos responsáveis pelo periódico e membros da Direção do CNF e da Administração Superior da FGV (notadamente Amaury Pereira Muniz e Irene Mello Carvalho); b) editoração privilegiada de artigos centrados sobre a ideia de didática como sendo o equivalente ao domínio de técnicas pedagógicas relacionadas a atividades de ensino, sem, no entanto explicitar a maneira como foram construídas no CNF e, menos ainda, por que motivo foram selecionadas para publicação em Curriculum .

A partir desses elementos pode-se afirmar que a ingerência da Direção do CNF e 
da Administração Superior da FGV na política editorial de Curriculum, se deu pela manutenção das posições relativas aos responsáveis pelo periódico. Esse aspecto fornece pistas importantes no sentido de que é possível inferir que durante o tempo de existência do $\mathrm{CNF}$, ocorreu uma centralização administrativa e a presença de um clima de coesão grupal no que se refere à unidade dos objetivos e coordenação das atividades relativas ao ensino no CNF.

\section{A escrita dos artigos sobre o CNF e as estratégias de divulgação de sua excelência}

Se nos artigos relativos ao tema "Didática", houve por parte de seus autores e por parte de seus responsáveis, a preocupação em apresenta-los a partir de um critério com base na excelência técnica das atividades desenvolvidas pelos docentes do CNF. Cabe ainda indicar que nos artigos cujo tema se remete ao CNF, destaca-se o tom de exaltação de duas dimensões do trabalho realizado no CNF: a) a excelência das atividades de ensino desenvolvidas pelos docentes; b) o destaque à "distinção moral" e à "competência acadêmica" da direção do CNF.

No tocante à primeira dimensão que aparece em destaque no discurso captado nos artigos sobre o CNF, torna-se necessário explicitar que em cada artigo cujo tema era o trabalho desenvolvido por algum dos professores do Colégio que revelava uma exaltação à competência técnica do(s) docente(s) responsável(eis) pelo trabalho em foco, privilegiando principalmente o realce dado à inovação daquela(s) atividade(s) de ensino desenvolvida(s) e citada(s) no(s) artigo(s). Depreende-se daí que, não obstante possam ter sido de grande competência os docentes do CNF, ainda assim, ao destacar num tom apologético as ações dos atores responsáveis pelas referidas atividades há uma estratégia de "elogio por amplificação das qualidades" (PERELMAN; OLBRECHTS-TYTECA, 2001), direcionado aos professores, e principalmente ao Colégio, com vistas a engrandecer o CNF frente às demais instituições de ensino do Brasil.

Em relação ao tratamento dado nos artigos sobre o CNF à "distinção moral" e à "competência acadêmica" dos responsáveis pelo Colégio e pelo periódico, convém explicitar que o referido realce a esses dois elementos do "discurso apologético" consistia em destacar os títulos acadêmicos de que eram portadores os referidos autores dos artigos, bem como identificar cada ato da administração mencionado à ideia de competência, segurança e brilhantismo no que refere à condução da instituição. Com isso, pode ser observado que, da mesma maneira como foi detectada uma estratégia de "elogio por amplificação", voltado para o coletivo do CNF quando se tratava de ressaltar os trabalhos desenvolvidos pelo corpo docente, a mesma estratégia seria direcionada para a esfera individual, ressaltando os elementos pessoais que contribuiriam para que a administração do CNF fosse tida como "segura", "brilhante" e "honesta".

Ao comparar os resultados indicados anteriormente na seção deste trabalho alusiva à seção Informações Pedagógicas com os resultados referentes à análise qualitativa dos artigos, é possível notar que ambas as seções utilizavam em seus textos um discurso de defesa da excelência do CNF e de seus professores, porém, se nas Informações Pedagógicas (principalmente no item "Registro CNF") era dada a ênfase na recordação dos "atos memoráveis" da história do CNF, com vistas, talvez a alçar a instituição de ensino a uma posição de destaque na história da educação brasileira, nos artigos sobre o Colégio era destacado o caráter de inovação e excelência que caracterizariam essa escola de iniciativa experimental, distinta de todas as demais e com aspirações a ser "a melhor escola de ensino médio do País". 


\section{As Sugestões Pedagógicas: a orientação didática do CNF e seus protagonistas}

Conforme foi possível perceber mediante a análise da matéria publicada nas seções Artigos, Conselho Editorial e Informações Pedagógicas, a divulgação das realizações e a amplificação dos elementos de "distinção moral", "competência técnica" e "excelência acadêmica" constituíram importante estratégia de divulgação do ideário pedagógico do CNF. Dando sequência ao esforço já empreendido, examinamos outro elemento de grande importância para a reconstrução da história do $\mathrm{CNF}$ e, mais diretamente, das estratégias condicionantes do periódico editado por esta instituição de ensino, trata-se da seção intitulada Sugestões.

Ao retomar a quantificação da matéria publicada na seção Sugestões, dois dados devem novamente ser trazidos à baila, são eles: a) a predominância do tema "Didática" em termos absolutos e relativos, mantendo um tom prescritivo ainda mais intenso do que nos artigos sobre o mesmo tema; b) Na maioria das sugestões consta a autoria da "Equipe de Professores do CNF" (60 de 105), porém após 1967, ano em que passa a constar a autoria individual de cada sugestão, Maria Zely de Souza Muniz (Chefe do Departamento de Línguas do CNF) é a autora que mais publica sugestões referentes ao tema "Didática".

No tocante ao primeiro resultado relativo à análise qualitativa da matéria da seção Sugestões, é possível perceber que o teor prescritivo, no sentido de divulgar "fórmulas" desenvolvidas no CNF e passíveis de serem aplicadas em outras escolas torna-se mais explícito nessa seção devido até mesmo ao fato dela ser, ao que tudo indica, o espaço privilegiado para que os docentes do Colégio pudessem expor os resultados de suas experiências no campo da didática (ainda que algumas dessas sugestões também versassem sobre Psicologia Educacional, Orientação Educacional/Pedagógica e outros temas). Necessário se torna também afirmar que o tom de "apologia ao trabalho desenvolvido no CNF" encontra-se explícito da mesma forma como ocorre em relação aos artigos, denotando mais uma vez a ideia de que os atores (e notadamente a direção do $\mathrm{CNF}$ ) tinham como objetivo fazer com que, mediante a leitura de Curriculum, não somente a ideia de excelência do $\mathrm{CNF}$ fosse veiculada, mas que, igualmente, devido às fórmulas e prescrições divulgadas neste periódico, fosse possível fazer do CNF uma instituição de referência no que se refere às escolas experimentais brasileiras.

Em relação à linha editorial de Curriculum, no que se refere à seção Sugestões, se verifica que durante o período que vai do ano de 1962 (ano de início da publicação da Revista) ao ano de 1967, a estratégia de atribuir autoria conjunta das sugestões reforça o discurso sobre a "competência técnica" do coletivo do CNF (em especial do corpo docente), sendo que, no período posterior, que vai de 1968 a 1976, essa estratégia de divulgação muda, passando a seção a destacar com maior ênfase as sugestões publicadas por aqueles autores que possuíam postos de destaque em relação ao CNF e à $\mathrm{FGV}^{6}$.

Tal mudança indica que nesse período teria ocorrido uma modificação na sua linha editorial que teria sido influenciada por uma mudança administrativa que estaria em curso e que culminaria em 1966 com uma modificação na organização administrativa do CNF, a qual teria como uma de suas principais medidas a extinção do Conselho Escolar (CARVALHO, 1988), o qual teria entre uma de suas prerrogativas a atribuição de organizar coletivamente o trabalho dos professores com a meta de divulgar esta produção através da seção da Revista, denominada Sugestões.

Desse modo, ao analisarmos a seção da matéria publicada em Curriculum, inferimos que por intermédio da seção intitulada Sugestões, o ideário pedagógico do CNF seria 
representado de maneira concreta, o que se daria mediante a utilização de atividades de ensino práticas direcionadas aos professores (especialmente aqueles ligados ao então denominado ensino de primeiro e segundo graus), o que, juntamente com os artigos consistiria numa estratégia de reforço da ideia de excelência acadêmica do CNF enquanto instituição de referência na pedagogia brasileira, devido à grande "utilidade" do material publicado na seção Sugestões.

\section{Considerações Finais}

O presente artigo não pretendeu esgotar todas as possibilidades de compreensão do periódico Curriculum e nem tampouco da instituição que lhe dava o suporte à consecução de seu projeto editorial. A análise empreendida serve de suporte para a compreensão aprofundada a respeito de experiências pedagógicas ainda pouco estudadas na historiografia da educação brasileira.

Desse modo, para além do tom apologético de suas realizações, contido no discurso dos atores institucionais do CNF, cumpre identificar a importância da Revista no sentido de divulgar a pedagogia experimental desenvolvida no CNF, instituição que contava com muitos recursos técnicos e financeiros durante o período de existência do periódico Curriculum. (CARVALHO, 1988; SANTOS, 2005).

Por último, mas nem por isso menos importante, cabe situar a Revista no âmbito de uma estratégia da FGV no sentido de promover a divulgação da sua memória institucional de modo a influenciar a educação brasileira a partir de seu discurso de excelência, configurando assim um modus operandi pautado na legitimação do seu tradicionalismo por intermédio da circulação de um impresso pedagógico especializado em experiências educacionais.

\section{Referências}

ALVARENGA, L. A Institucionalização da Pesquisa Educacional no Brasil. Tese de Doutorado apresentada ao Programa de Pós-Graduação em Educação da Universidade Federal de Minas Gerais. Belo Horizonte, MG: UFMG, 1996.

Colégio Nova Friburgo da Fundação Getúlio Vargas: histórico de suas realizações. Rio de Janeiro, RJ: Editora FGV, 1988.

CHARTIER, Roger. A História Cultural: entre práticas e representações. Tradução de Maria Manoela Galhardo. Rio de Janeiro: Bertrand Brasil, 1993.

CURY, Carlos Roberto Jamil. Educação e Contradição. Campinas, SP: Cortez, 1996.

FÁVERO, M. L. A. A experiência do IESAE/FGV: das origens à extinção. Revista Movimento. v1, n. 8, abril de 2002, Niterói, RJ: EDUFF 2002.

HALBWACHS, M. A Memória Coletiva. Tradução de Laurent Leon Schaffter. São Paulo, SP: Vértice, 1984.

HOUAISS, Antonio. Dicionário Houaiss. São Paulo, SP: Objetiva, 2001.

LE GOFF, J. Historia. In: Enciclopédia Einaudi, v.1, Memória-História. Porto: Inova/Artes Gráficas, Imprensa Nacional - Casa da Moeda, 1985, p. 158-178.

PEIXOTO, M. C. L. A Educação Superior em Cinco Periódicos: Debate e Crítica, Ciências Sociais Hoje, Revista Brasileira de Ciências Sociais, Boletim Bibliográfico e Fórum 
Educacional. In: MOROSINI, Marilia, SGUISSARDI, Waldemar (Orgs.). A Educação Superior em Periódicos Nacionais. Vitória, ES: FCAA, 1996.

PERELMAN, Chain, OLBRECHTS-TYTECA, Lucie. Tratado da Argumentação: a Nova Retórica. Tradução de Regina K. Pupi. São Paulo, SP: Martins Fontes, 2001.

SANTOS, P. S. M. B. O Colégio Nova Friburgo da Fundação Getúlio Vargas: mergulhando em sua memória institucional. Rio de Janeiro: PUC-Rio, Departamento de Educação, 2005.

\section{Notas}

${ }^{1}$ Universidade Federal Fluminense. Email: psmbs@vm.uff.br

2 A noção de Memória Institucional consistiria em uma aplicação do conceito de Memória Coletiva, construído por Maurice Halbwachs, o qual situa a questão da Memória para uma perspectiva que vai para além dos limites da subjetividade humana, indo em direção à sua presença material e concreta nas manifestações coletivas de interação social tais como eventos culturais e tradições consolidadas em comportamentos. (HALBWACHS, 1984).

${ }^{3}$ No número 01, relativo ao semestre compreendido entre janeiro e junho de 1962, por exemplo, figurava na capa um retrato do ilustre matemático grego Pitágoras.

${ }^{4}$ Como exemplo pode ser destacado o convênio de cooperação técnica e aperfeiçoamento de professores firmado entre o Colégio Nova Friburgo, o Ministério da Educação e Cultura, a Secretaria de Educação do Estado do Rio de Janeiro, cuja referência encontra-se na seção Registro CNF do número 17 relativo ao mês de junho de 1968.

${ }^{5}$ Ao longo dos quinze anos em que fui publicado, o Periódico apresentava a seguinte composição de seu Conselho Editorial: Prof Irene Mello Carvalho (Diretora do Conselho Editorial), Prof. Amaury Pereira Muniz (Redator-chefe), e, Professores Antonio Savino e Sérgio Fernandes Costa Bustamantes (Secretários da Revista).

${ }^{6}$ Como prova disso, temos o número total de 18 sugestões (aproximadamente 40,0\%) publicadas entre 1968 e 1974 se tomarmos em separado aquelas cuja autoria remonta a Maria Zely de Souza Muniz, Amury Pereira Muniz e Irene Mello Carvalho.

Recebido em março-13

Aprovado em outubro-13 